\title{
Screening and Identifying m6A Regulators as an Independent Prognostic Biomarker in Pancreatic Cancer Based on The Cancer Genome Atlas Database
}

\author{
Bi Lin $\left(D,{ }^{1}\right.$ Yangyang Pan, ${ }^{2}$ Dinglai Yu, ${ }^{3}$ Shengjie Dai $\left({ }^{\circ},{ }^{3}\right.$ Hongwei Sun, ${ }^{3}$ Shengchuan Chen, ${ }^{3}$ \\ Jie Zhang, ${ }^{3}$ Yukai Xiang $\left(\mathbb{0},{ }^{3}\right.$ and Chaohao Huang $\mathbb{\circledR}^{3}$ \\ ${ }^{1}$ Department of Anesthesiology, The First Affiliated Hospital of Wenzhou Medical University, Wenzhou, China \\ ${ }^{2}$ Department of Emergency Medicine, Yinzhou Second Hospital, Ningbo, Zhejiang, China \\ ${ }^{3}$ Department of Hepatological Surgery, The First Affiliated Hospital of Wenzhou Medical University, Wenzhou, China \\ Correspondence should be addressed to Chaohao Huang; kirbylin2010@sina.com
}

Received 8 February 2021; Revised 13 April 2021; Accepted 19 April 2021; Published 17 May 2021

Academic Editor: Paul Harrison

Copyright ( $2021 \mathrm{Bi}$ Lin et al. This is an open access article distributed under the Creative Commons Attribution License, which permits unrestricted use, distribution, and reproduction in any medium, provided the original work is properly cited.

\begin{abstract}
Background. Pancreatic cancer is one of the most malignant tumors of the digestive system, and its treatment has rarely progressed for the last two decades. Studies on m6A regulators for the past few years have seemingly provided a novel approach for malignant tumor therapy. m6A-related factors may be potential biomarkers and therapeutic targets. This research is focused on the gene characteristics and clinical values of m6A regulators in predicting prognosis in pancreatic cancer. Methods. In our study, we obtained gene expression profiles with copy number variation (CNV) data and clinical characteristic data of 186 patients with pancreatic cancer from The Cancer Genome Atlas (TCGA) portal. Then, we determined the alteration of m6a regulators and their correlation with clinicopathological features using the log-rank tests, Cox regression model, and chi-square test. Additionally, we validated the prognostic value of m6A regulators in the International Cancer Genome Consortium (ICGC). Results. The results suggested that pancreatic cancer patients with ALKBH5 CNV were associated with worse overall survival and disease-free survival than those with diploid genes. Additionally, upregulation of the writer gene ALKBH5 had a positive correlation with the activation of AKT pathways in the TCGA database. Conclusion. Our study not only demonstrated genetic characteristic changes of m6A-related genes in pancreatic cancer and found a strong relationship between the changes of $A L K B H 5$ and poor prognosis but also provided a novel therapeutic target for pancreatic cancer therapy.
\end{abstract}

\section{Introduction}

Pancreatic cancer, especially pancreatic ductal adenocarcinoma (PDAC), is one of the most malignant tumors of the digestive system, causing approximately 350,000 deaths worldwide every year [1]. By the year of 2030, PDAC would be the second leading cause of cancer-related mortality, surpassing lung cancer and colorectal cancer [2]. Although extensive studies on pancreatic cancer have been conducted over the past few decades, there is no substantial improvement in the prognosis of pancreatic cancer. The most optimal choice and therapeutic strategy for pancreatic cancer are still surgical resection combined with chemotherapy, but the unresectability rate is still high, and the 5 -year overall sur- vival (OS) rate remains $<7 \%$, accompanied with a continuous elevation of its incidence [1]. To date, there are still no reliable gene signatures for treatment effects and prognosis and for early detection and improved therapies. Therefore, there is an urgent need to develop a method to predict whether a patient will have a relatively long survival time and better prognosis, based on the characteristics of transcriptome sequencing and genome sequencing. Screening and uncovering potential biomarkers of tumor heterogeneity have become a focus in cancer research [3], and most of the candidate genes for therapeutic target are closely related to pathogenic gene variants or to their tumor tissue-specific antigens [4-6]. Many problems related to pancreatic cancer treatment remain to be solved, especially in the field of exploring the 
TABLE 1: Mutations of m6A regulatory genes in 186 PDAC patients.

\begin{tabular}{|c|c|c|c|c|c|c|c|}
\hline $\begin{array}{l}\text { PAAD sample } \\
\text { ID }\end{array}$ & ALKBH5 & FTO & METTL14 & METTL3 & WTAP & YTHDF1 YTHDF2 & YTHDC1 \\
\hline TCGA-IB-7651 & $\mathrm{R} 327 \mathrm{H}$ & $\mathrm{R} 473 \mathrm{~W}$ & & & & & \\
\hline $\begin{array}{l}\text { TCGA-F2- } \\
\text { A44G }\end{array}$ & & & $\begin{array}{l}\text { R298H, X23_ } \\
\text { splice }\end{array}$ & & & & \\
\hline $\begin{array}{l}\text { TCGA-2J- } \\
\text { AABV }\end{array}$ & & & & $\mathrm{R} 471 \mathrm{H}$ & & & \\
\hline TCGA-IB-7651 & & & & A191V & & & \\
\hline TCGA-IB-7644 & & & & & C161Y & & \\
\hline $\begin{array}{l}\text { TCGA-HZ- } \\
\text { A9TJ }\end{array}$ & & & & & $\begin{array}{l}\text { X49- } \\
\text { splice }\end{array}$ & & \\
\hline $\begin{array}{l}\text { TCGA-IB- } \\
\text { AAUS }\end{array}$ & & & & & $\mathrm{K} 155 \mathrm{E}$ & & \\
\hline TCGA-IB-A5SQ & & & & & & $\mathrm{R} 404 \mathrm{C}$ & \\
\hline TCGA-IB-7651 & & & & & & & $\begin{array}{c}\text { K565N, X374_splice, E224K, } \\
\text { Q168H }\end{array}$ \\
\hline
\end{tabular}

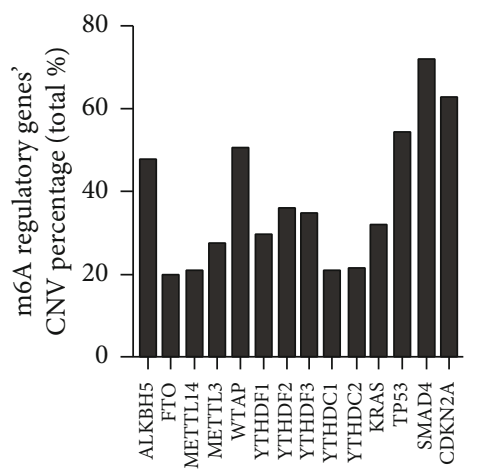

(a)

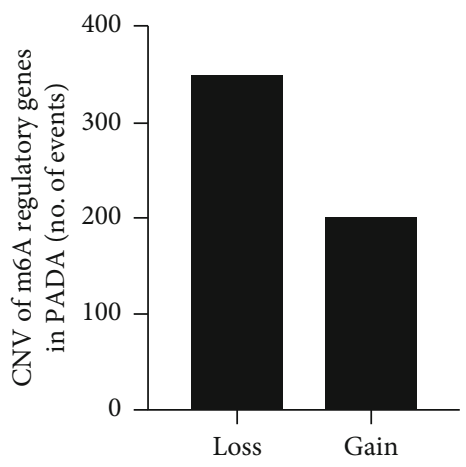

(b)

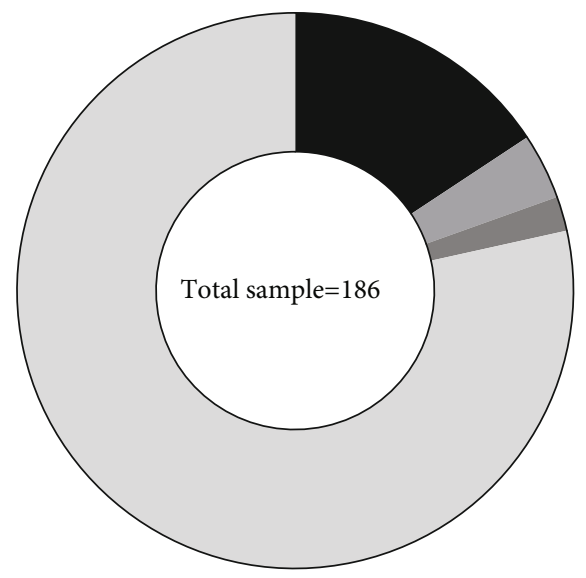

$15.69 \%$ Most frequent single gene CNV

(shallow deletion of WTAP)

$3.83 \%$ Most frequent double gene CNV (ALKBH5

shallow deletion with $Y T H D F 3$ copy number gain)

$2.01 \%$ No CNVs

$78.47 \%$ Other CNV Pattens

(c)

FIgURE 1: CNV characteristics of m6A regulatory genes in PAAD. (a) Percentage of PAAD samples with CNVs of m6A regulators, based on the data from TCGA. (b) Events of copy number gain or loss of m6A regulatory genes in PAAD samples. (c) The most common patterns of CNVs in m6A regulatory genes in the PAAD samples. 
TABLE 2: Different CNV patterns occur in PAAD samples $(n=177)$.

\begin{tabular}{|c|c|c|c|c|c|c|c|c|}
\hline & & Diploid & Deep deletion & Shallow deletion & Copy number gain & Amplification & CNV sum & Percentage \\
\hline \multirow{2}{*}{ Eraser } & ALKBH5 & 92 & & 73 & 9 & 3 & 85 & $48.02 \%$ \\
\hline & FTO & 142 & & 12 & 22 & 1 & 35 & $19.8 \%$ \\
\hline \multirow{3}{*}{ Writers } & METTL14 & 140 & & 28 & 9 & & 37 & $20.9 \%$ \\
\hline & METTL3 & 128 & & 19 & 29 & 1 & 49 & $27.7 \%$ \\
\hline & WTAP & 87 & & 86 & 4 & & 90 & $50.8 \%$ \\
\hline \multirow{9}{*}{ Reader } & YTHDF1 & 125 & & 7 & 44 & 1 & 52 & $29.4 \%$ \\
\hline & YTHDF2 & 113 & 1 & 58 & 5 & & 64 & $36.2 \%$ \\
\hline & YTHDF3 & 115 & & 17 & 40 & 5 & 62 & $35 \%$ \\
\hline & YTHDC1 & 141 & 1 & 26 & 9 & & 36 & $20.3 \%$ \\
\hline & YTHDC2 & 139 & & 22 & 16 & & 38 & $21.5 \%$ \\
\hline & KRAS & 120 & 1 & 14 & 36 & 6 & 57 & $32.2 \%$ \\
\hline & TP53 & 81 & 2 & 86 & 8 & & 96 & $54.2 \%$ \\
\hline & SMAD4 & 50 & 25 & 95 & 7 & & 127 & $71.8 \%$ \\
\hline & CDKN2A & 66 & 49 & 60 & 2 & & 111 & $62.7 \%$ \\
\hline
\end{tabular}

underlying molecular mechanisms of the tumorigenesis of pancreatic cancer and new therapeutic targets.

In the last few decades, chemical modifications of nucleobases have become a focus in controlling gene expression in cancers at different levels because of their subsequent regulation in protein translation and modulation of signaling pathways, especially N6-methyladenosine (m6A) modification. $\mathrm{m} 6 \mathrm{~A}$ has been considered the major type of normal endogenous modification on RNA molecules including mRNAs [6], miRNAs [7], and lncRNAs [8]. Additionally, m6A modification has been confirmed to be a reversible process dependent on multiple m6A regulatory enzymes, which are classified as "writers (WTAP, METTL3, and METTL14)," "erasers (FTO and ALKBH5)," and "readers (YTHDF1, YTHDF2, YTHDF3, YTHDC1, and YTHDC2)" [9].

The effects of m6A are mainly determined by m6A readers, writers, and erasers. The writer complex includes methylase enzymes, while the erasers downregulate the $\mathrm{m} 6 \mathrm{~A}$ level. Furthermore, the readers regulate the balance between writers and erasers, sequentially producing a functional signal [10]. Dysregulation of m6A results in multiple physiological homeostasis dysfunctions and affects the tumorigenesis and progression of most human malignancies through various mechanisms [11]. Therefore, m6A regulatory gene alternation also plays a vital role in multiple pathogenic mechanisms of human disease, especially in tumorigenesis [12]. However, the underlying mechanism of m6A regulatory genes is complex and involves multiple molecules and pathways [13]. Dysregulation of $\mathrm{m} 6 \mathrm{~A}$ regulatory genes in various cancers results in cancer cell EMT [14], apoptosis [15], and stem cell self-renewal [16], which are important in cancer progression. However, the relationship between $\mathrm{m} 6 \mathrm{~A}$ regulatory genes and pancreatic cancer is still unclear. Therefore, in our study, we obtained the RNAsequencing (RNA-Seq) gene expression profiles and patients' clinical information of 186 patients with pancreatic adeno- carcinoma (PAAD) from The Cancer Genome Atlas (TCGA). Among them, we evaluated the change profiles of $10 \mathrm{~m} 6 \mathrm{~A}$ regulatory genes in pancreatic cancer and the relationship between these changes and clinicopathologic features, including survival. Finally, an alteration of $A L K B H 5$ was identified, which could be considered a biomarker for prognosis or a therapeutic target for pancreatic cancer therapy.

\section{Methods}

2.1. Data Processing. From the TCGA database, we analyzed the copy number variation $(\mathrm{CNV})$ data and pathology reports of a total of 186 patients with pancreatic cancer. The up-and-down regulation CNV was assessed using segmentation analysis and the GISTIC algorithm. Next, to explore the relationship between the clinicopathological significance of $\mathrm{PAAD}$ patients and $\mathrm{m} 6 \mathrm{~A}$ regulatory genes, the cohort of 186 pancreatic cancer patients was divided into two groups: "with mutation and/or CNVs of these m6A regulatory genes" and "without CNVs and mutation." The mRNA expression data profiles of patients with pancreatic cancer were also acquired from the TCGA database, and then, the mRNA expression levels were processed with the log scale, exploring the association with CNVs.

Then, we acquired the clinical information and mRNA expression data profiles of patients with pancreatic cancer form Australia. After the data with ambiguous variables were excluded, the remaining 82 patients were processed by $\mathrm{R}$ software ( $\mathrm{R}$ 4.0.3) with survival packages and GSEA software (GSEA 3.0).

2.2. Gene Set Enrichment Analysis (GSEA). GSEA software (GSEA 3.0) was downloaded from the website (https://www .gsea-msigdb.org/gsea/index.jsp) [16]. Herein, according to the expression level of $A L K B H 5$, GSEA divided the PAAD 
TABLE 3: Clinical pathological parameters of PAAD patients with or without mutation/CNV of $\mathrm{m} 6 \mathrm{~A}$ regulatory genes*.

\begin{tabular}{|c|c|c|c|c|}
\hline & & $\begin{array}{c}\text { With } \\
\text { mutation } \\
\text { and/or } \mathrm{CNV}^{*}\end{array}$ & $\begin{array}{c}\text { Without } \\
\text { mutation and } \\
\mathrm{CNV}^{*}\end{array}$ & $p$ \\
\hline \multirow{2}{*}{ Age } & $\leq 60$ & 14 & 44 & \multirow{2}{*}{0.695} \\
\hline & $>60$ & 32 & 87 & \\
\hline \multirow{2}{*}{ Gender } & Male & 18 & 79 & \multirow{2}{*}{$0.013^{*}$} \\
\hline & Female & 28 & 52 & \\
\hline \multirow{6}{*}{$\begin{array}{l}\text { Pathological } \\
\text { stage }\end{array}$} & I & 2 & 5 & \multirow{6}{*}{0.670} \\
\hline & II & 9 & 15 & \\
\hline & III & 34 & 107 & \\
\hline & IV & 1 & 2 & \\
\hline & Discrepancy & 0 & 1 & \\
\hline & N/A & 0 & 1 & \\
\hline \multirow{5}{*}{$\begin{array}{l}\text { Historical } \\
\text { grade }\end{array}$} & G1 & 13 & 17 & \multirow{5}{*}{$0.035^{*}$} \\
\hline & G2 & 24 & 71 & \\
\hline & G3 & 7 & 41 & \\
\hline & G4 & 1 & 1 & \\
\hline & $\mathrm{Gx}$ & 1 & 1 & \\
\hline \multirow{6}{*}{ T stage } & $\mathrm{T} 1$ & 9 & 12 & \multirow{6}{*}{0.328} \\
\hline & $\mathrm{T} 2$ & 35 & 111 & \\
\hline & T3 & 1 & 2 & \\
\hline & $\mathrm{T} 4$ & 1 & 3 & \\
\hline & $\mathrm{Tx}$ & 0 & 3 & \\
\hline & NA & 0 & 3 & \\
\hline \multirow{3}{*}{ M stage } & M0 & 23 & 57 & \multirow{3}{*}{0.870} \\
\hline & M1 & 1 & 3 & \\
\hline & $\mathrm{Mx}$ & 22 & 71 & \\
\hline \multirow{4}{*}{$\mathrm{N}$ stage } & N0 & 12 & 37 & \multirow{4}{*}{0.673} \\
\hline & N1 & 34 & 89 & \\
\hline & $\mathrm{Nx}$ & 0 & 4 & \\
\hline & NA & 0 & 1 & \\
\hline
\end{tabular}

${ }^{*}$ With mutation or CNV: cases have mutant or $\mathrm{CNV}$ or mutant $+\mathrm{CNV}$, confirmed through TCGA database. Without mutant and CNV: cases with neither mutant nor CNV, confirmed through TCGA database. Ambiguous variables $(\mathrm{Nx}, \mathrm{Mx}, \mathrm{N} / \mathrm{A}$, discrepancy, and $\mathrm{Gx})$ were excluded from chisquare test or nonparametric test. ${ }^{*} p$ value $<0.005$.

samples into two groups (ALKBH5-high group and ALKBH5-low group). Afterwards, the hallmark gene set "c2.cp.biocarta.v6.0.symbols.gmt" was set up in the GSEA to analyze 19726 genes involved in PAAD, and those with normalized $p$ value $<0.05$ were considered to be significantly enriched.

2.3. Statistical Analysis. SPSS 22.0 (IBM, Chicago, USA) and GraphPad Prism 7.0 (GraphPad Software, La Jolla, CA, USA) were applied to analyze the data. Our study adopted the $\chi^{2}$ test or Mann-Whitney $U$ test to determine the relationship between $\mathrm{m} 6 \mathrm{~A}$ regulatory genes with different alternations and clinical characteristics of PAAD patients. The Kaplan-
TABLE 4: Relationship between molecular characteristics and m6A regulatory gene alteration in PAAD patients.

\begin{tabular}{lccccc}
\hline & & $\begin{array}{c}\text { Without } \\
\text { mutation } \\
\text { or CNV }\end{array}$ & $\begin{array}{c}\text { With } \\
\text { mutation } \\
\text { and } \\
\mathrm{CNV}^{*}\end{array}$ & $\chi^{2}$ & $p$ \\
\hline KRAS & Wt & 45 & 75 & 25.671 & $p<0.001^{*}$ \\
& Alteration & 1 & 56 & & \\
SMAD4 & Wt & 32 & 18 & 52.346 & $p<0.001^{*}$ \\
& Alteration & 14 & 113 & & \\
TP53 & Wt & 42 & 39 & 51.936 & $p<0.001^{*}$ \\
& Alteration & 4 & 92 & & \\
CDKN2A & Wt & 42 & 24 & 77.551 & $p<0.001^{*}$ \\
& Alteration & 4 & 107 & & \\
\hline
\end{tabular}

${ }^{*} p$ value $<0.005$

Meier curve and the log-rank test were adopted for analyzing the OS or/and disease-free survival (DFS) with m6A gene regulators. Then, a Cox proportional hazard regression model was used to analyze the relationship between m6A regulatory genes and clinicopathological characteristics of PAAD patients in terms of OS and DFS. A $p$ value $<0.05$ was considered to indicate a statistically significant difference.

\section{Results}

3.1. Mutations and CNVs of m6A Regulatory Genes in Patients with PAAD. Within the TCGA database, only 19 independent samples were found to have mutations of $\mathrm{m} 6 \mathrm{~A}$ regulatory genes (Table 1), among the 186 cases based on the sequencing data; however, CNVs in ten m6A-related genes were observed in 177 PAAD samples based on the $\mathrm{CNV}$ data (Figure 1(a)). The results showed that the m6A "writer" gene WTAP had the highest frequency of CNV events $(50.8 \%, 90 / 177)$ followed by ALKBH5 (48.02\%, 85/177), which is an m6A "eraser" gene. Furthermore, we also investigated the frequency of CNVs in KRAS (32.2\%), TP53 (54.2\%), SMAD4 (71.8\%), and CDKN2A (62.7\%) in this cohort.

Next, we determined the CNVs of the above ten m6A regulatory genes in the PAAD samples and found that the loss of the copy number was the most frequent CNV event (350/548) (Figure 1(b) and Table 2), which was the same as the CNV status in clear cell renal cell carcinoma (ccRCC) [17]. Among these CNVs, shallow deletion of WTAP ranked as the first in terms of the most frequent CNVs, and shallow deletion of both ALKBH5 and YTHDF3 was the most frequent cooccurring $\mathrm{CNV}$, indicating the important roles these two genes play in the process of m6A RNA modification.

3.2. Alterations of m6A Regulatory Genes Are Associated with Clinicopathological and Molecular Characteristics. We also assessed the association between variations (CNV and/or mutation) of the m6A-related regulators and the clinicopathological features of patients with PAAD. Similar to the 


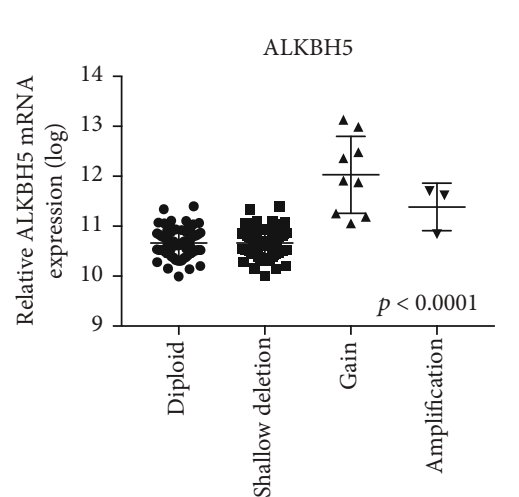

(a)

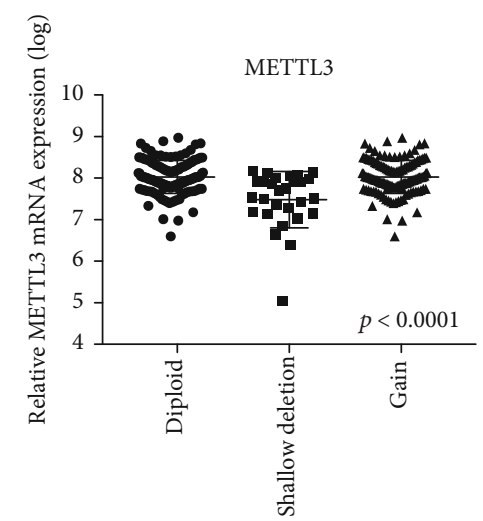

(d)

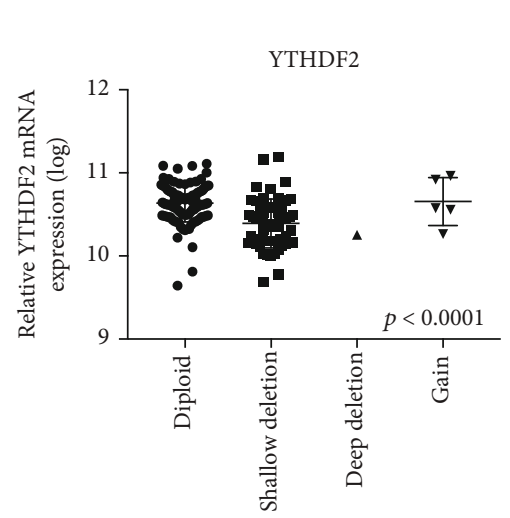

(g)

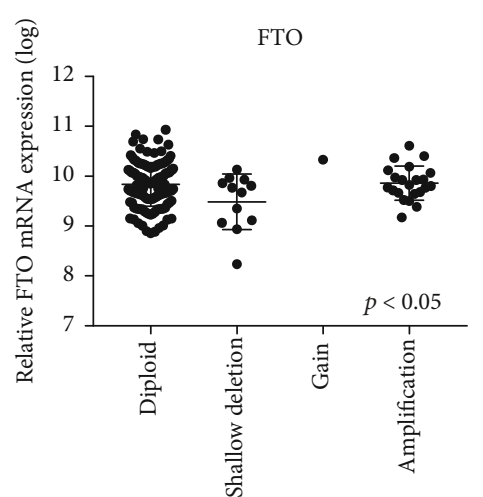

(b)

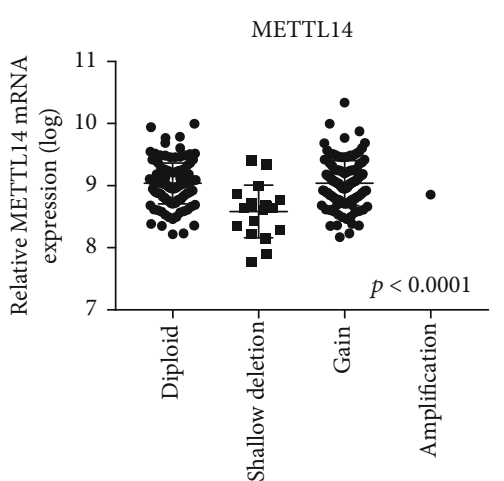

(c)

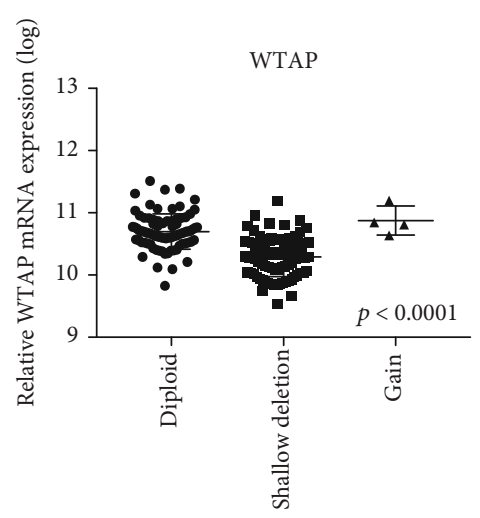

(e)

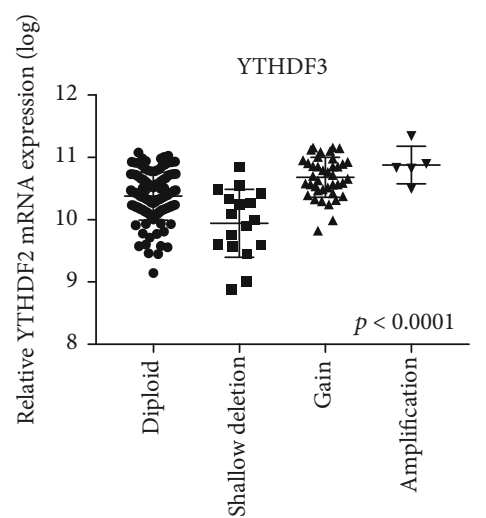

(h)

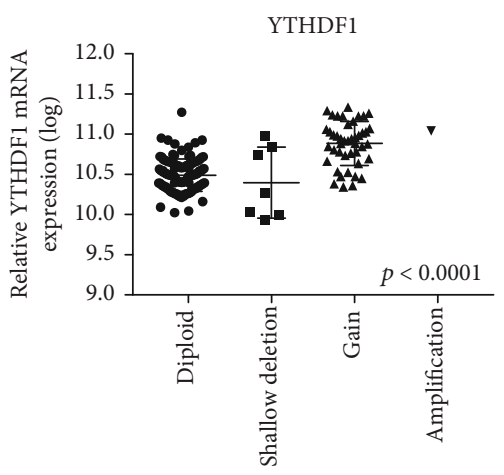

(f)

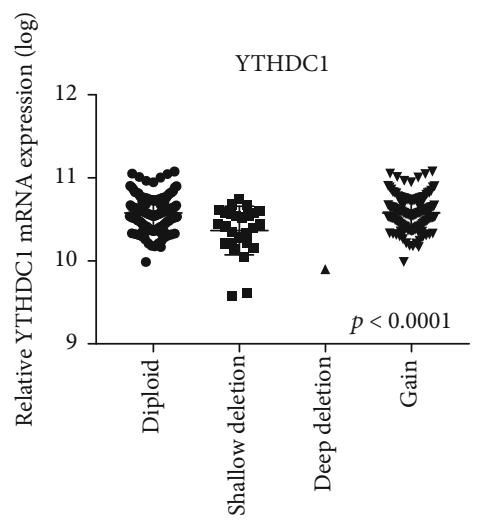

(i)

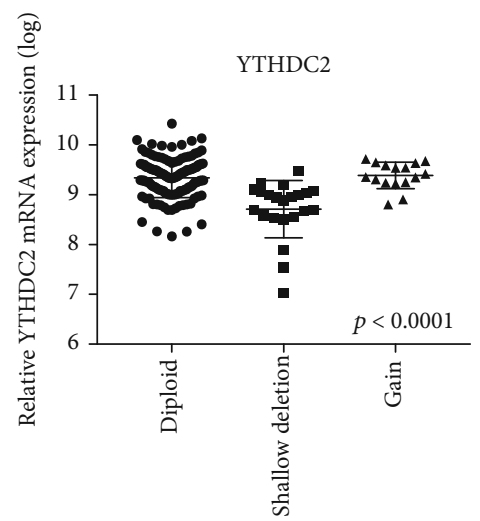

(j)

FIgURE 2: The relationship between different CNV patterns and mRNA expression levels of ten m6A regulatory genes in PAAD samples. 


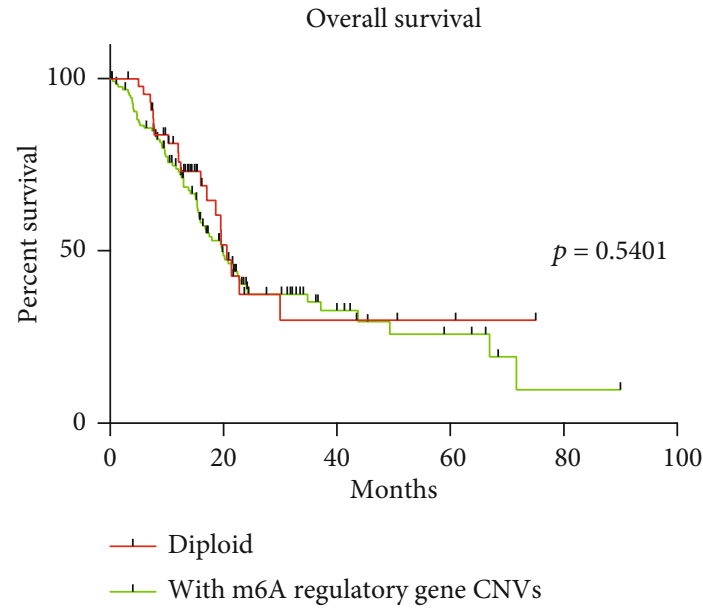

(a)

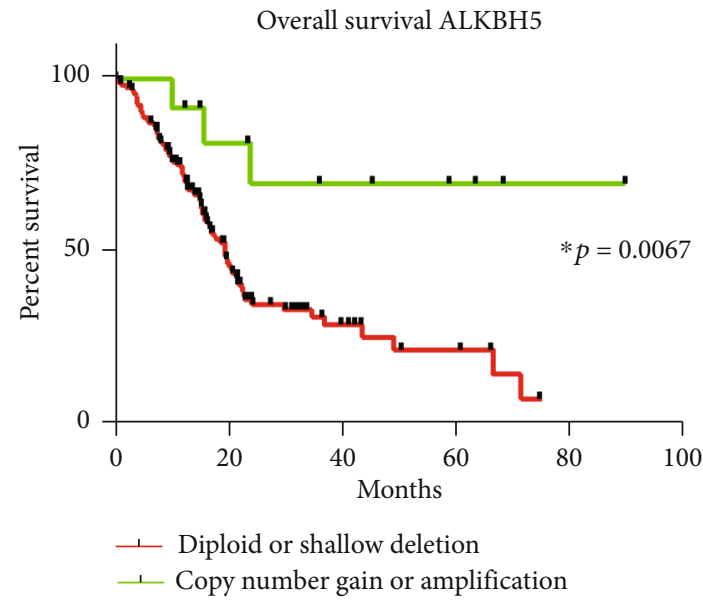

(c)

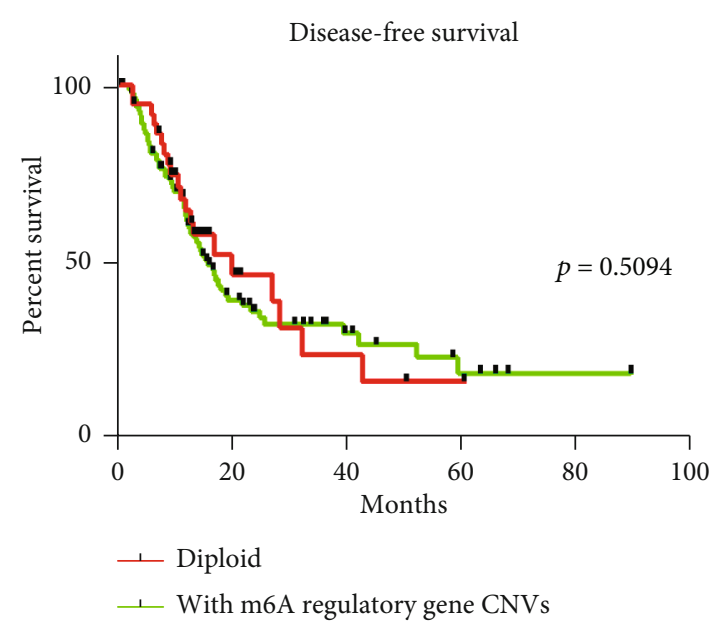

(b)

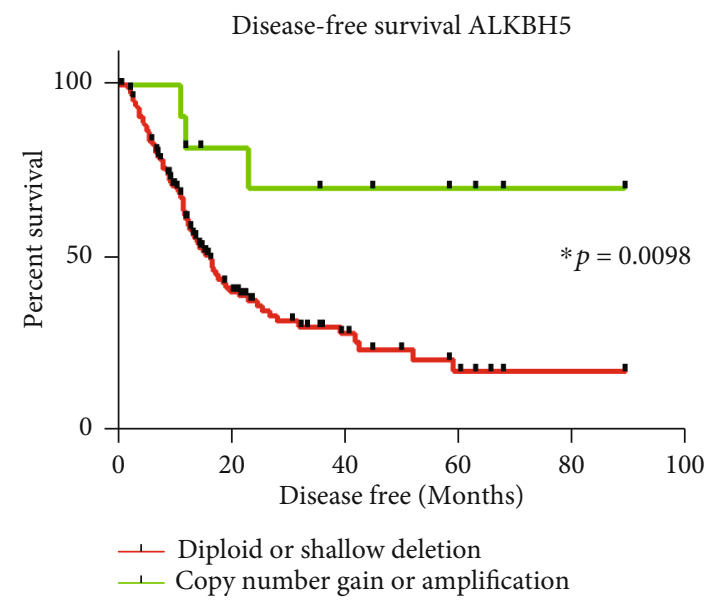

(d)

FIgure 3: The overall survival of patients with PAAD with CNVs of m6A regulatory genes. (a, b) OS and DFS of patients with any of the CNVs of m6A regulatory genes or with diploid genes. (c, d) OS and DFS of patients with different CNV types of ALKBH5.

ccRCC samples, the results of this study showed a close correlation between alterations of $\mathrm{m} 6 \mathrm{~A}$ regulatory genes and higher Fuhrman Nuclear Grade (Table 3) in PAAD samples. On account of the fact that KRAS, TP53, SMAD4, and $C D K N 2 A$ play important roles in the tumorigenesis of $\mathrm{PAAD}$, we also assessed whether alterations of $\mathrm{m} 6 \mathrm{~A}$ regulatory genes were related to alterations of these four genes or not. As shown in Table 4, KRAS, TP53, SMAD4, and $C D K N 2 A$ alterations in PAAD samples had a positive correlation with alterations of $\mathrm{m} 6 \mathrm{~A}$ regulatory genes as expected; meanwhile, one sample showed no alterations of m6A regulatory genes among the total 57 patients with KRAS CNV.

Furthermore, we also evaluated the association between the $\mathrm{m} 6 \mathrm{~A}$ regulatory genes and $\mathrm{mRNA}$ expression. The results revealed that the ubiquitous $\mathrm{CNV}$ s were associated with the mRNA expression levels of m6A-related genes in 177 PAAD samples. Among these genes, the copy number gains were positively associated with higher mRNA expression, whereas the shallow deletions or deep deletions were negatively associated with lower mRNA expression (Figure 2).
3.3. Identification of the Prognostic Value of $m 6$ A Regulatory Gene CNVs in Patients with PAAD. The CNV effects of m6A regulatory genes on the OS and DFS of patients with PAAD were evaluated. As shown in Figures 3(a) and 3 (b), there was no correlation between m6A regulatory gene CNVs and OS/DFS among patients with PAAD. Furthermore, a separate analysis of the ten $\mathrm{m} 6 \mathrm{~A}$ regulatory genes revealed a significant difference between patients with PAAD and those with alterations of ALKBH5 (one eraser gene of m6A). Copy number gain or amplification with ALKBH5 showed better OS and DFS (Figures 3(c) and 3(d)); however, according to survival analysis of the CNVs of the other nine m6Aregulated genes, no significant differences were observed between the different separated subgroups (Figure S1). Additionally, ALKBH5 was determined as an independent risk factor for OS and DFS, as shown in Table 5. Combined with the results presented above, we suggested that PAAD patients with upregulated ALKBH5 mRNA expression have a better survival. 
TABLE 5: Univariate and multivariate COX regression analyses of m6A regulatory genes for PAAD patients' overall survival (OS) and diseasefree survival (DFS)*.

\begin{tabular}{|c|c|c|c|c|c|c|c|c|}
\hline \multirow{3}{*}{ Variable } & \multicolumn{4}{|c|}{ OS } & \multicolumn{4}{|c|}{ DFS } \\
\hline & \multicolumn{2}{|c|}{ Univariate } & \multicolumn{2}{|c|}{ Multivariate } & \multirow{2}{*}{$\begin{array}{c}\text { Univariate } \\
\text { HR }(95 \% \text { CI })\end{array}$} & \multirow{2}{*}{$\begin{array}{c}\text { Multivariate } \\
p\end{array}$} & \multirow{2}{*}{$\begin{array}{c}\text { Univariate } \\
\text { HR }\end{array}$} & \multirow{2}{*}{$\begin{array}{c}\text { Multivariate } \\
p\end{array}$} \\
\hline & HR (95\% CI) & $p$ & HR & $p$ & & & & \\
\hline Age (>60 vs. $\leq 60)$ & $\begin{array}{c}1.383(0.883- \\
20165)\end{array}$ & 0.156 & $\begin{array}{c}1.387(0.854- \\
2.253)\end{array}$ & 0.187 & $\begin{array}{c}0.976(0.622- \\
1.533)\end{array}$ & 0.917 & $\begin{array}{c}0.733(0.446- \\
1.205)\end{array}$ & 0.221 \\
\hline Gender (male vs. female) & $\begin{array}{c}1.192(0.793- \\
1.792)\end{array}$ & 0.398 & $\begin{array}{c}1.561(0.962- \\
2.533)\end{array}$ & 0.071 & $\begin{array}{c}1.137(0.732- \\
1.767)\end{array}$ & 0.568 & $\begin{array}{c}1.506(0.887- \\
2.556)\end{array}$ & 0.129 \\
\hline Stage (I-II vs. III-IV) & $\begin{array}{c}1.165(0.835- \\
1.624)\end{array}$ & 0.369 & $\begin{array}{c}1.168(0.574- \\
2.376)\end{array}$ & 0.669 & $\begin{array}{l}2.120(1.111- \\
4.047)\end{array}$ & $0.023^{*}$ & $\begin{array}{c}1.162(0.576- \\
2.346)\end{array}$ & 0.675 \\
\hline M (M1 vs. M0) & $\begin{array}{c}1.050(0.251- \\
4.388)\end{array}$ & 0.947 & & & $\begin{array}{l}0.936(0.226- \\
3.885)\end{array}$ & 0.928 & & \\
\hline N (N1 vs. N0) & $\begin{array}{l}2.151(1.281- \\
3.612)\end{array}$ & $0.004^{*}$ & $\begin{array}{l}2.119(1.184- \\
3.793)\end{array}$ & $0.011^{*}$ & $\begin{array}{c}1.750(1.065- \\
2.875)\end{array}$ & $0.027^{*}$ & $\begin{array}{c}1.488(0.844- \\
2.623)\end{array}$ & 0.169 \\
\hline T (T3-T4 vs. T1-T2) & $\begin{array}{c}0.92(0.250- \\
2.513)\end{array}$ & 0.693 & $\begin{array}{c}0.878(0.258- \\
2.987)\end{array}$ & 0.835 & $\begin{array}{c}1.078(0.339- \\
3.431)\end{array}$ & 0.898 & $\begin{array}{c}1.455(0.419- \\
5.056)\end{array}$ & 0.555 \\
\hline Grade (3-5 vs. $1-2$ ) & $\begin{array}{c}1.496(0.970- \\
2.308)\end{array}$ & 0.069 & $\begin{array}{c}1.146(0.709- \\
1.854)\end{array}$ & 0.578 & $\begin{array}{l}1.740(1.094- \\
2.767)\end{array}$ & 0.019 & $\begin{array}{c}1.424(0.854- \\
2.375)\end{array}$ & 0.175 \\
\hline KRAS (altered vs. diploid) & $\begin{array}{l}1.170(0.75- \\
1.825)\end{array}$ & 0.490 & $\begin{array}{l}1.836(1.058- \\
3.185)\end{array}$ & $0.031^{*}$ & $\begin{array}{c}0.890(0.547- \\
1.449)\end{array}$ & 0.640 & $\begin{array}{c}1.673(0.869- \\
3.219)\end{array}$ & 0.123 \\
\hline TP53 (altered vs. diploid) & $\begin{array}{c}1.242(0.817- \\
1.889)\end{array}$ & 0.311 & $\begin{array}{c}1.140(0.672- \\
1.932)\end{array}$ & 0.628 & $\begin{array}{c}0.986(0.634- \\
1.533)\end{array}$ & 0.950 & $\begin{array}{c}0.986(0.561- \\
1.732)\end{array}$ & 0.961 \\
\hline $\begin{array}{l}\text { SMAD4 (altered vs. } \\
\text { diploid) }\end{array}$ & $\begin{array}{c}1.234(0.766- \\
1.987)\end{array}$ & 0.387 & $\begin{array}{c}1.066(0.590- \\
1.926)\end{array}$ & 0.831 & $\begin{array}{c}1.653(0.976- \\
2.800)\end{array}$ & 0.062 & $\begin{array}{l}1.095(0.568- \\
2.110)\end{array}$ & 0.786 \\
\hline $\begin{array}{l}\text { CDKN2A (altered vs. } \\
\text { diploid) }\end{array}$ & $\begin{array}{c}1.307(0.837- \\
2.042)\end{array}$ & 0.238 & $\begin{array}{c}0.950(0.667- \\
1.352)\end{array}$ & 0.774 & $\begin{array}{c}1.480(0.929- \\
2.356)\end{array}$ & 0.099 & $\begin{array}{c}0.915(0.619- \\
1.353)\end{array}$ & 0.657 \\
\hline $\begin{array}{l}\text { WTAP (write loss vs. } \\
\text { others) }\end{array}$ & $\begin{array}{c}1.325(0.879- \\
1.998)\end{array}$ & 0.179 & $\begin{array}{l}1.291(0.799- \\
2.085)\end{array}$ & 0.298 & $\begin{array}{c}1.245(0.802- \\
1.932)\end{array}$ & 0.329 & $\begin{array}{c}1.255(0.729- \\
2.162)\end{array}$ & 0.412 \\
\hline $\begin{array}{l}\text { Mettl3 (write loss vs. } \\
\text { others) }\end{array}$ & $\begin{array}{l}0.918(0.488- \\
1.725)\end{array}$ & 0.790 & $\begin{array}{c}0.648(0.308- \\
1.364)\end{array}$ & 0.253 & $\begin{array}{c}1.269(0.670- \\
2.403)\end{array}$ & 0.464 & $\begin{array}{c}0.869(0.405- \\
1.867)\end{array}$ & 0.720 \\
\hline $\begin{array}{l}\text { Mettl14 (write loss vs. } \\
\text { others) }\end{array}$ & $\begin{array}{c}1.199(0.707- \\
2.034)\end{array}$ & 0.501 & $\begin{array}{c}1.378(0.747- \\
2.543)\end{array}$ & 0.305 & $\begin{array}{c}1.639(0.956- \\
2.812)\end{array}$ & 0.073 & $\begin{array}{l}1.970(1.037- \\
3.741)\end{array}$ & $0.038^{*}$ \\
\hline $\begin{array}{l}\text { FTO (eraser gain vs. } \\
\text { others) }\end{array}$ & $\begin{array}{c}1.236(0.684- \\
2.234)\end{array}$ & 0.483 & $\begin{array}{c}0.968(0.483- \\
1.942)\end{array}$ & 0.928 & $\begin{array}{c}1.490(0.799- \\
2.778)\end{array}$ & 0.209 & $\begin{array}{c}1.062(0.499- \\
2.263)\end{array}$ & 0.875 \\
\hline $\begin{array}{l}\text { ALKBH5 (eraser gain vs. } \\
\text { others) }\end{array}$ & $\begin{array}{l}0.229(0.072- \\
0.731)\end{array}$ & $0.013^{*}$ & $\begin{array}{c}0.287(0.083- \\
0.988)\end{array}$ & $0.048^{*}$ & $\begin{array}{l}0.199(0.062- \\
0.641)\end{array}$ & $0.007^{*}$ & $\begin{array}{l}0.201(0.053- \\
0.763)\end{array}$ & $0.018^{*}$ \\
\hline
\end{tabular}

${ }^{*}$ Ambiguous variables $(\mathrm{Nx}, \mathrm{Mx}, \mathrm{N} / \mathrm{A}$, discrepancy, and $\mathrm{Gx})$ were excluded. ${ }^{*} p$ value $<0.005$.

3.4. Enrichment Analysis of ALKBH5 Gain of Function. To confirm the abovementioned conclusion of the relationship between upregulated ALKBH5 expression and better and prolonged survival, we next evaluated the ALKBH5 mRNA expression among patients with PAAD whose prognoses were affected by the ALKBH5 mRNA level in Gene Expression Profiling and Interactive Analyses (GEPIA, http://gepia .cancer-pku.cn/index.html) [18]. As expected, patients with low ALKBH5 mRNA expression had worse OS than those with high $A L K B H 5$ expression (Figure 4(a)). However, the ALKBH5 mRNA expression level had no statistically significant association with DFS in patients with PAAD (Figure 4(b)). Considering ALKBH5 as an "eraser" in the demethylation process, combining with the results of our study, we attempted to explore the dysregulation of ALKBH5 in the pathogenesis of patients with PAAD. We examined the enriched gene sets in the TCGA data sample with different ALKBH5 mRNA expression levels with GSEA. GSEA analysis showed that the differential expression of ALKBH5 was related to some key biological processes involving PGC1A, AKT, and longevity signaling pathways (Table 6 and Figures 4(c) and 4(d)), thus providing an indication of the underlying mechanism in the tumorigenesis of PAAD. Additionally, several studies have found that ALKBH5 can participate in AKT signaling pathways, consistent with our assumption [19]. Further study is still needed to illustrate the potential effects of $A L K B H 5$ on the regulation of the downstream genes in pancreatic cancer.

3.5. Validating the Prognostic Value of $m 6 A$ Regulators in ICGC Database. To confirm the prognostic value of alternative $\mathrm{m} 6 \mathrm{~A}$ regulators, we also analyze the $\mathrm{m} 6 \mathrm{~A}$ regulators in 


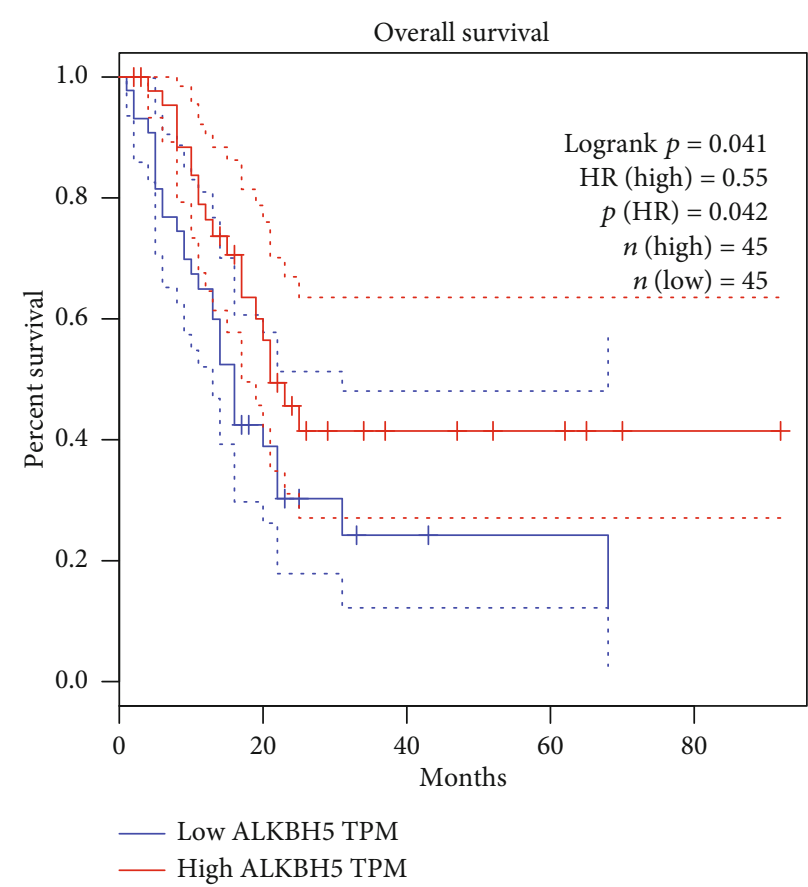

(a)

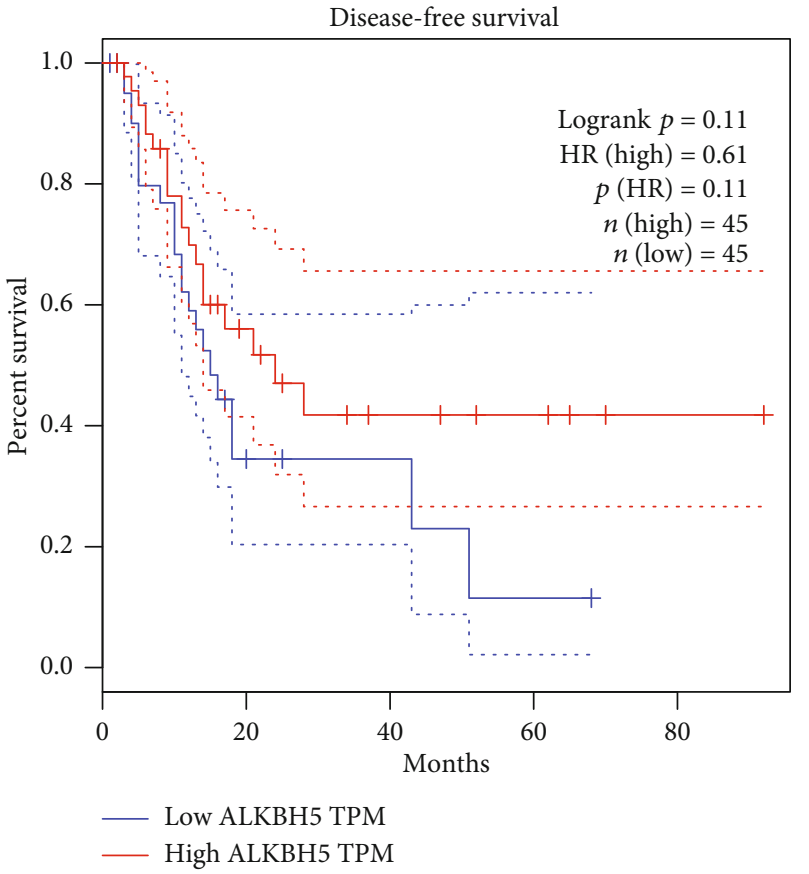

(b)

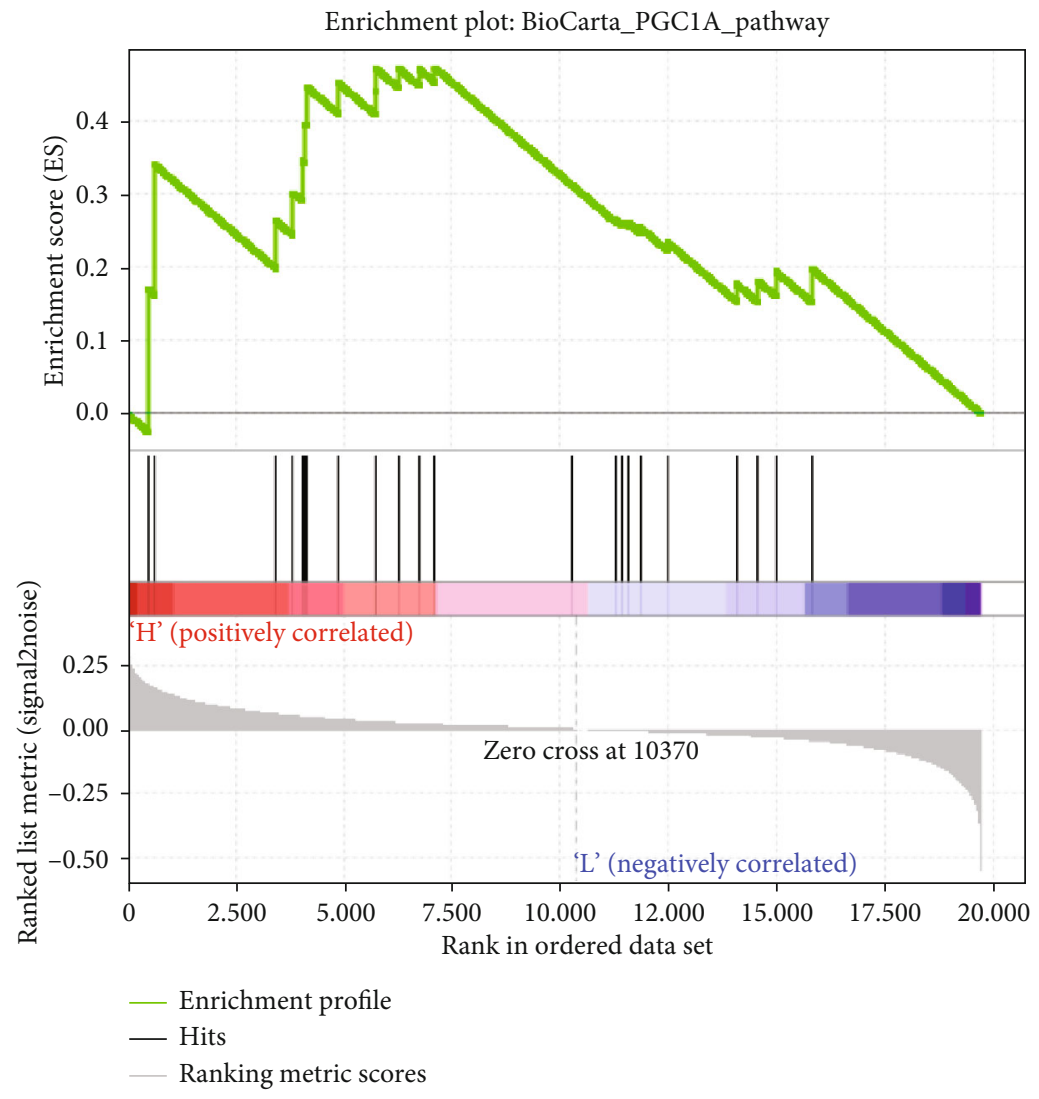

(c)

FIgURE 4: Continued. 


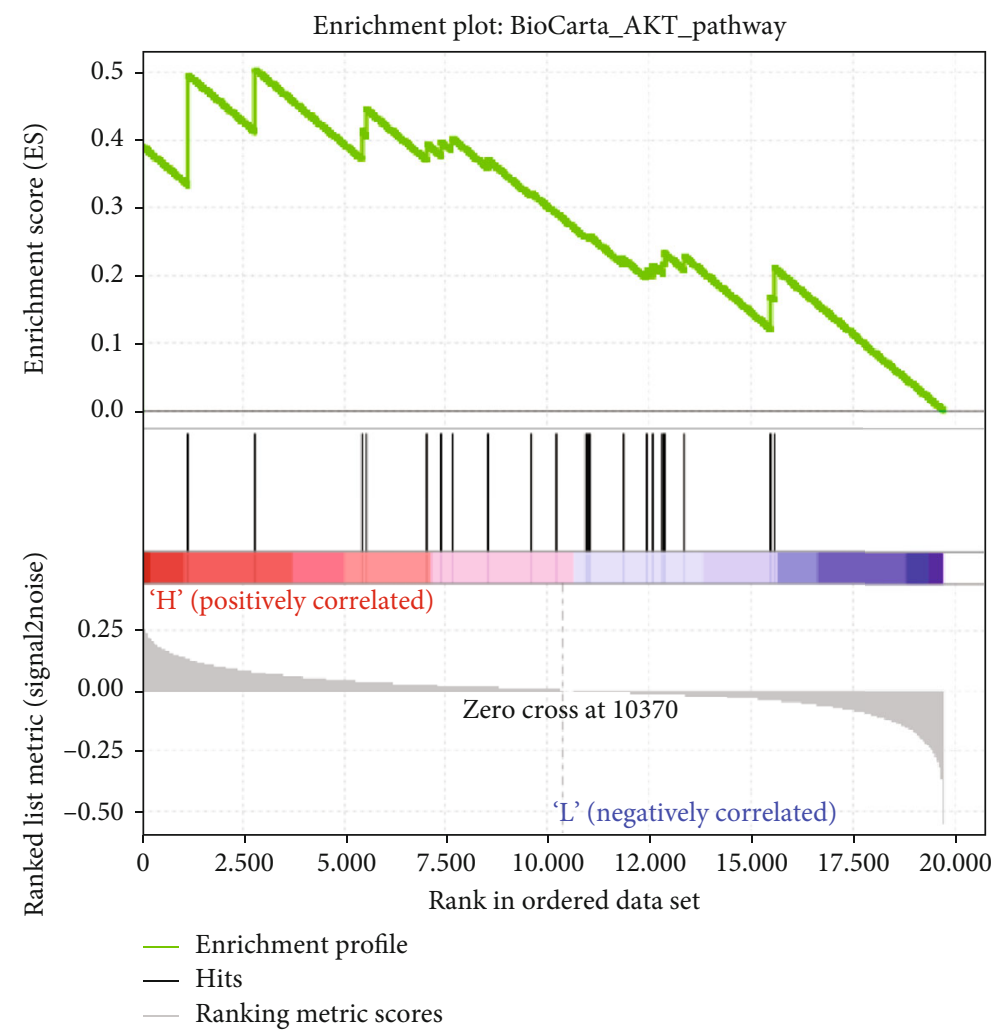

(d)

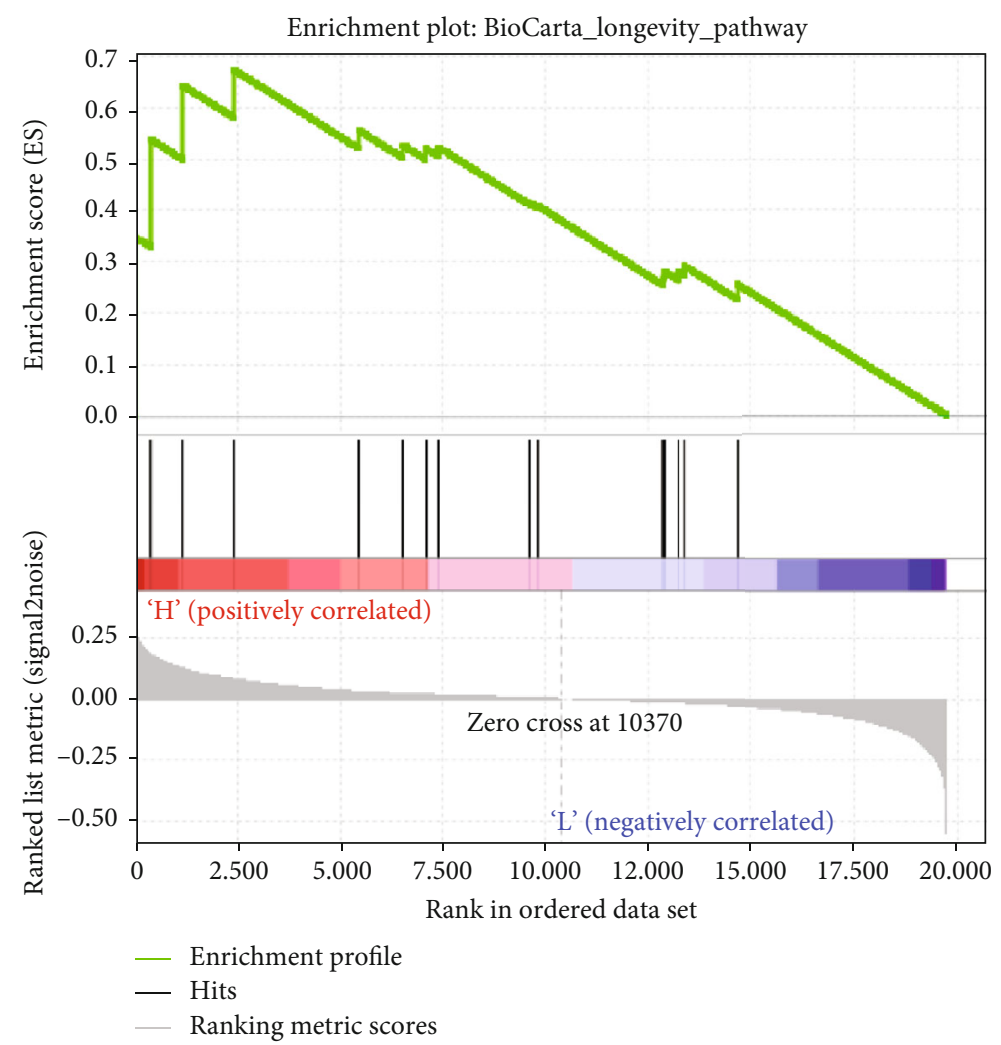

(e)

Figure 4: Functions of different expression levels of ALKBH5 in TCGA. (a, b) OS and DFS of patients with different ALKBH5 mRNA levels. Gene set enrichment plots of (c) PGC1A, (d) AKT signaling, and (e) longevity to ALKBH5 mRNA levels in the PAAD samples. 
TABLE 6: Gene set enrichment of low ALKBH5 mRNA expression level in the PAAD cohort of TCGA.

\begin{tabular}{lcccc}
\hline GS details & Size & ES & NES & NOM $p$ value \\
\hline BioCarta_PGC1A_pathway & 23 & 0.53 & 1.60 & $0.029^{*}$ \\
BioCarta_AKT_pathway & 22 & 0.54 & 1.53 & $0.046^{*}$ \\
BioCarta_longevity_pathway & 15 & 0.66 & 1.47 & $0.028^{*}$ \\
\hline
\end{tabular}

${ }^{*} p$ value $<0.005$.

the ICGC database. The same in the TCGA database, patients with low ALKBH5 mRNA expression had worse OS than those with high $A L K B H 5$ expression (Figure 5(a)). Moreover, patients with a higher YTHDF2 expression were observed to have a better overall survival (Figure 5(b)). Except for the above two genes, age, gender, and the expression of other m6A regulators had no significant differences with OS survival. However, GSEA analysis showed that the differential expression of $A L K B H 5$ in ICGC was only related to PGC1A signaling pathways (Table 7 and Figure 5(c)). The different results presented in the two databases might have resulted from the data offset because of the relatively small sample size.

\section{Discussion}

Pancreatic cancer is one of the most common malignancies of the digestive system, and progress in research related to its treatment has been slow. In recent decades, the discovery of m6A has increased our understanding of tumorigenesis regulation to a new level, helping us gain insight into the role of methylation and demethylation in tumor formation and progression [20]. Many studies have demonstrated that $\mathrm{m} 6 \mathrm{~A}$ alternation is one of the key factors in cancer management [21]. However, the role of $\mathrm{m} 6 \mathrm{~A}$ regulatory genes in pancreatic cancer remains unclear. Upon analysis of the different expressions or mutations of "readers," "writers," and "erasers" in different tissues, we found that the genes related to $\mathrm{m} 6 \mathrm{~A}$ regulation seem to be different in distant tumors. Therefore, in this study, we aimed to screen and uncover m6A regulatory factors closely related to clinicopathological significance and prognosis in pancreatic cancer. This study not only determined the value of $\mathrm{m} 6 \mathrm{~A}$ regulatory genes for pancreatic cancer prognosis but also proposed a novel therapeutic target for pancreatic cancer.

As a demethylase, ALKBH5 is involved in the mediation of methylation reversal. It has been reported that ALKBH5 is overexpressed in various cancers, including breast cancer [22], glioblastoma [23], ovarian cancer [24], and gastric cancer $[25,26]$. Additionally, signaling associated with multiple cancers is dysregulated in PAAD development. We found that in patients with PAAD, a high ALKBH5 mRNA expression level was associated with the activation of AKT signaling pathways, which participate in important cellular pathological processes in PAAD development [27], suggesting that the mRNAs of molecules in the AKT pathway may be the m6a modification target mediated by ALKBH5 [28]. Recently, a study has shown that ALKBH5 functions as an antitumor protein in pancreatic cancer progression [29]; in this paper, upregulated ALKBH5 sensitized pancreatic cancer to gemcitabine chemotherapy, and knockdown of ALKBH5 decreased pancreatic cancer cell invasion, migration, proliferation, metastasis, and tumorigenesis [29]. As in the case of colorectal cancer [30], ALKBH5 showed obviously weaker mRNA expression in pancreatic cancer than in the normal tissue. However, in contrast to the case of rectal adenocarcinoma wherein high $A L K B H 5$ expression in tumor tissues was clearly associated with worse OS, ALKBH5 expression in pancreatic cancer was found to be positively associated with OS in TCGA and ICGC, which was in accordance with the report by Cho et al. [31]. Compared with their study, we screened the 9 more m6A regulators and explored the CNV in the public database, evaluated the copy number variation $(\mathrm{CNV})$ data of m6A on the OS and DFS of patients with PAAD, and further verified the prognostic value of ALKBH5 in pancreatic cancer.

We also evaluated the effect of $\mathrm{m} 6 \mathrm{~A}$ regulatory gene alterations on the survival of patients with PAAD. In line with the characteristics of genetic alterations of m6A-related genes, the eraser gene ALKBH5 was the only gene among the ten regulators that was associated with the OS and DFS. This confirmed that "erasers" are the main regulators of $\mathrm{m} 6 \mathrm{~A}$ in PAAD. A better OS was observed in patients with eraser gene gain of function, making it clear that a decreased level of m6A plays a significant role in PAAD progression. However, we failed to obtain any significant results with regard to the relationship between the other nine $\mathrm{m} 6 \mathrm{~A}$ regulatory gene alterations and OS or DFS, possibly because of the limited number of patients. Direct detection of the m6A level and evaluation of its effect on PAAD survival in a new and larger cohort are needed to illustrate this contradictory phenomenon.

We also assessed the impact of m6A-related gene changes on prognosis, especially OS and DFS, in patients with PAAD. According to the genetic changes of m6Arelated gene characteristics, only ALKBH5, an eraser gene, was associated with OS and DFS among the 10 regulatory genes. This confirms that erasers might be the predominant governors of $\mathrm{m} 6 \mathrm{~A}$ in PAAD. The patients with gained function of $A L K B H 5$ achieved better OS, indicating that decreased m6A levels may play an important role in the progression of PAAD. Since the different results of YTHDF2 and ALKBH5 were presented in the ICGC database, we were unable to derive any significant results on the relationship between the other nine $\mathrm{m} 6 \mathrm{~A}$ regulatory gene changes and OS or DFS, possibly due to the limited number of patients and database heterogeneity. To account for this paradox, m6A levels need to be directly detected, and their impact on PAAD survival should be evaluated in a new and larger cohort.

In conclusion, we screened alternations of ten $\mathrm{m} 6 \mathrm{~A}$ regulatory genes in the TCGA database of pancreatic cancer patients and identified that $A L K B H 5$ was the most valuable prognosis-related gene that may be associated with AKT signaling pathways. These findings revealed a novel molecular 


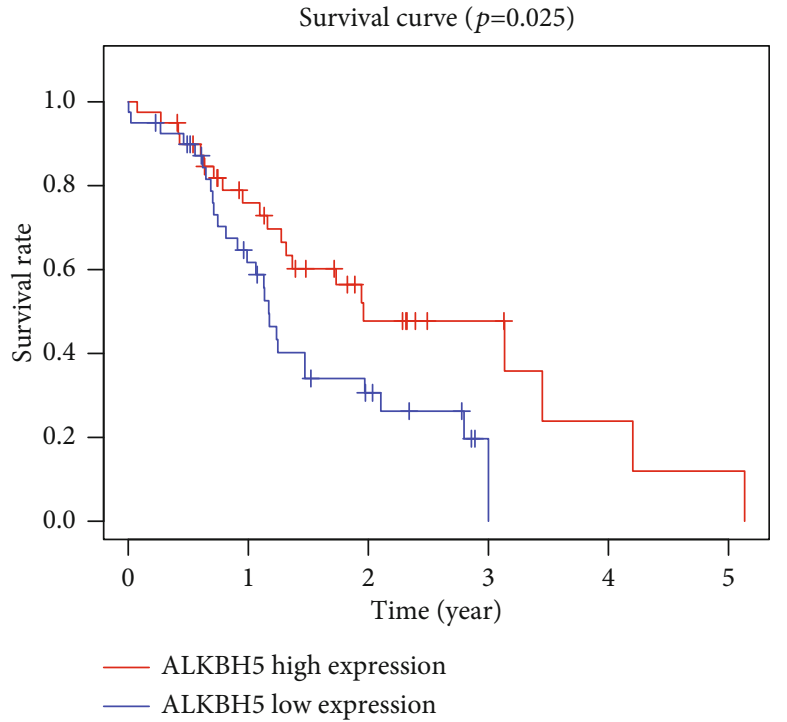

(a)

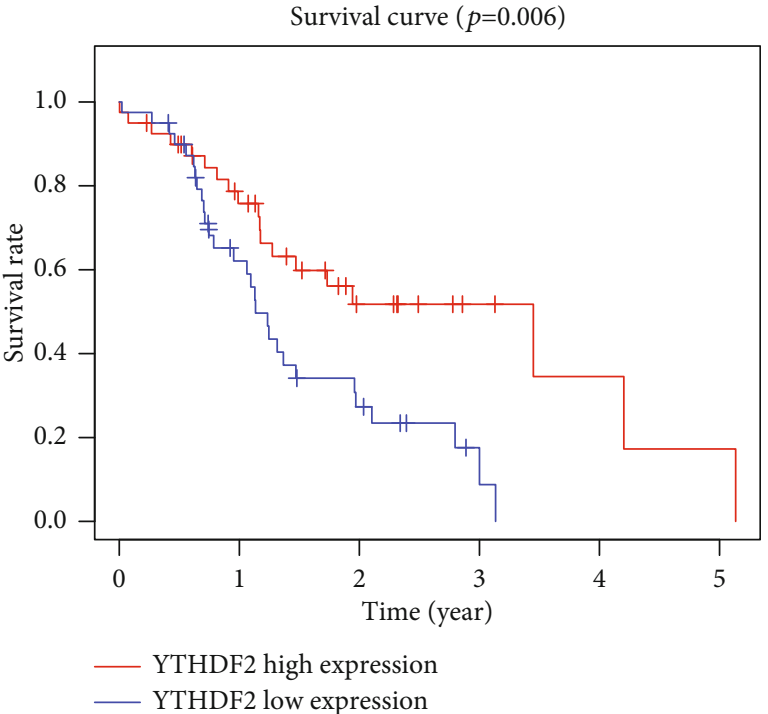

(b)

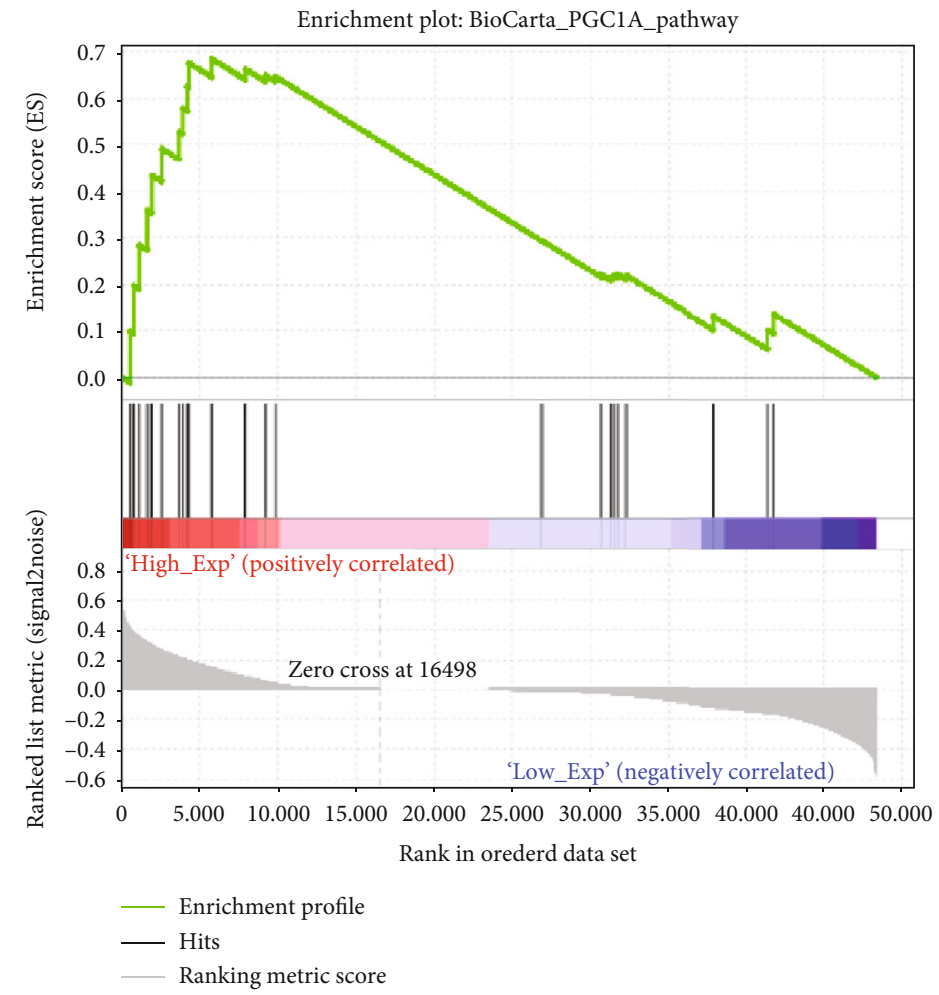

(c)

Figure 5: Functions of different expression levels of ALKBH5 in ICGC. (a, b) OS of patients with different ALKBH5 and YTHDF2 mRNA levels. Gene set enrichment plots of (c) PGC1A to ALKBH5 mRNA levels in the pancreatic cancer samples.

TABLE 7: Gene set enrichment of low ALKBH5 mRNA expression level in the PAAD cohort ICGC.

\begin{tabular}{lcccc}
\hline GS details & Size & ES & NES & NOM $p$ value \\
\hline BioCarta_PGC1A_pathway & 23 & 0.68 & 1.50 & $0.031^{*}$ \\
BioCarta_AKT_pathway & 21 & 0.67 & 1.39 & 0.091 \\
BioCarta_longevity_pathway & 15 & 0.59 & 1.22 & 0.214 \\
\hline
\end{tabular}

${ }^{*} p$ value $<0.005$. mechanism of PDAC tumorigenesis regulated by m6A modification and provided a new insight into the development of effective therapeutic strategies for the treatment of pancreatic cancer. Although we provided robust evidence for the prognostic value of the effect of ALKBH5 on pancreatic cancer, the underlying mechanism is not yet fully characterized. Thus, the effects of ALKBH5 clearly deserve further investigation. 


\section{Data Availability}

Publicly available datasets were analyzed in this study; these can be found in the International Cancer Genome Consortium (https://daco.icgc.org/) and The Cancer Genome Atlas (https://portal.gdc.cancer.gov/) by the cBioPortal platform and TCGA-Assembler, which are open to the public under some guidelines. The data analyzed during the current study are available from the corresponding author on reasonable request.

\section{Consent}

All the clinical and sequencing data were downloaded from the public database TCGA according to relevant user guidelines. Therefore, it can be ascertained that all patients provided written informed consent.

\section{Disclosure}

The manuscript has a preprint on Research Square: https:// assets.researchsquare.com/files/rs-96939/v1.

\section{Conflicts of Interest}

The authors have no conflicts of interest to declare.

\section{Authors' Contributions}

The study conception and design were performed by Chaohao Huang. Material preparation, data collection, and analysis were performed by Dinglai Yu, Yangyang Pan, Hongwei Sun, and Shengjie Dai. The first draft of the manuscript was written by Chaohao Huang and Bi Lin. All authors commented on previous versions of the manuscript. All authors read and approved the final manuscript.

\section{Acknowledgments}

We would like to thank Editage (http://www.editage.cn) for the English language editing. The work was supported by the funds from the PhD Start-Up Funding of the First Affiliated Hospital of Wenzhou Medical University, Zhejiang, China (No. 2019QD004).

\section{Supplementary Materials}

Figure S1: overall survival of patients with PAAD with CNVs of $\mathrm{m} 6 \mathrm{~A}$ regulatory genes excluding ALKBH5. (Supplementary Materials)

\section{References}

[1] A. L. Lucas, M. Malvezzi, G. Carioli et al., "Global trends in pancreatic cancer mortality from 1980 through 2013 and predictions for 2017," Clinical Gastroenterology and Hepatology, vol. 14, no. 10, pp. 1452-1462.e4, 2016.

[2] L. Rahib, B. D. Smith, R. Aizenberg, A. B. Rosenzweig, J. M. Fleshman, and L. M. Matrisian, "Projecting cancer incidence and deaths to 2030: the unexpected burden of thyroid, liver, and pancreas cancers in the United States," Cancer Research, vol. 74, no. 11, pp. 2913-2921, 2014.

[3] N. McGranahan and C. Swanton, "Clonal heterogeneity and tumor evolution: past, present, and the future," Cell, vol. 168, no. 4, pp. 613-628, 2017.

[4] M. H. Bailey, C. Tokheim, E. Porta-Pardo et al., "Comprehensive characterization of cancer driver genes and mutations," Cell, vol. 174, no. 4, pp. 1034-1035, 2018.

[5] A. J. Aguirre, J. A. Nowak, N. D. Camarda et al., "Real-time genomic characterization of advanced pancreatic cancer to enable precision medicine," Cancer Discovery, vol. 8, no. 9, pp. 1096-1111, 2018.

[6] V. P. Balachandran, M. Łuksza, J. N. Zhao et al., "Identification of unique neoantigen qualities in long-term survivors of pancreatic cancer," Nature, vol. 551, no. 7681, pp. 512-516, 2017.

[7] C. R. Alarcon, H. Goodarzi, H. Lee, X. Liu, S. Tavazoie, and S. F. Tavazoie, "HNRNPA2B1 is a mediator of $\mathrm{m}^{6} \mathrm{~A}$-dependent nuclear RNA processing events," Cell, vol. 162, no. 6, pp. 1299-1308, 2015.

[8] D. Yang, J. Qiao, G. Wang et al., "N6-methyladenosine modification of lincRNA 1281 is critically required for mESC differentiation potential," Nucleic Acids Research, vol. 46, no. 8, pp. 3906-3920, 2018.

[9] K. D. Meyer and S. R. Jaffrey, "Rethinking m6A readers, writers, and erasers," Annual Review of Cell and Developmental Biology, vol. 33, no. 1, pp. 319-342, 2017.

[10] W. Zheng, X. Dong, Y. Zhao et al., "Multiple functions and mechanisms underlying the role of METTL3 in human cancers," Frontiers in Oncology, vol. 9, p. 1403, 2019.

[11] T. Liu, Q. Wei, J. Jin et al., "The $\mathrm{m}^{6} \mathrm{~A}$ reader YTHDF1 promotes ovarian cancer progression via augmenting EIF3C translation," Nucleic Acids Research, vol. 48, no. 7, pp. 3816$3831,2020$.

[12] Y. Meng, S. Li, D. Gu et al., "Genetic variants in $\mathrm{m}^{6} \mathrm{~A}$ modification genes are associated with colorectal cancer risk," Carcinogenesis, vol. 41, 2020.

[13] S. Y. Zhang, S. W. Zhang, X. N. Fan et al., "Global analysis of N6-methyladenosine functions and its disease association using deep learning and network-based methods," PLoS Computational Biology, vol. 15, no. 1, article e1006663, 2019.

[14] B. Yue, C. Song, L. Yang et al., "METTL3-mediated N6methyladenosine modification is critical for epithelialmesenchymal transition and metastasis of gastric cancer," Molecular Cancer, vol. 18, no. 1, p. 142, 2019.

[15] J. Paris, M. Morgan, J. Campos et al., "Targeting the RNA m ${ }^{6}$ A Reader YTHDF2 Selectively Compromises Cancer Stem Cells in Acute Myeloid Leukemia," Cell Stem Cell, vol. 25, no. 1, pp. 137-148.e6, 2019.

[16] R. Jia, P. Chai, S. Wang et al., " $\mathrm{m}^{6} \mathrm{~A}$ modification suppresses ocular melanoma through modulating HINT2 mRNA translation," Molecular Cancer, vol. 18, no. 1, p. 161, 2019.

[17] J. Zhou, J. Wang, B. Hong et al., "Gene signatures and prognostic values of $\mathrm{m} 6 \mathrm{~A}$ regulators in clear cell renal cell carcinoma - a retrospective study using TCGA database," Aging, vol. 11, no. 6, pp. 1633-1647, 2019.

[18] Z. Tang, C. Li, B. Kang, G. Gao, C. Li, and Z. Zhang, "GEPIA: a web server for cancer and normal gene expression profiling and interactive analyses," Nucleic Acids Research, vol. 45, no. W1, pp. W98-W102, 2017.

[19] C. Zhang, M. Zhang, S. Ge et al., "Reduced m6A modification predicts malignant phenotypes and augmented Wnt/PI3K- 
Akt signaling in gastric cancer," Cancer Medicine, vol. 8, no. 10, pp. 4766-4781, 2019.

[20] S. Wang, P. Chai, R. Jia, and R. Jia, "Novel insights on $\mathrm{m}^{6} \mathrm{~A}$ RNA methylation in tumorigenesis: a double-edged sword," Molecular Cancer, vol. 17, no. 1, p. 101, 2018.

[21] N. Pinello, S. Sun, and J. J. Wong, "Aberrant expression of enzymes regulating $\mathrm{m}^{6} \mathrm{~A}$ mRNA methylation: implication in cancer," Cancer Biology \& Medicine, vol. 15, no. 4, pp. 323334, 2018.

[22] C. Zhang, D. Samanta, H. Lu et al., "Hypoxia induces the breast cancer stem cell phenotype by HIF-dependent and ALKBH5-mediated m6A-demethylation of NANOG mRNA," Proceedings of the National Academy of Sciences of the United States of America, vol. 113, no. 14, pp. E2047-E2056, 2016.

[23] S. Zhang, B. S. Zhao, A. Zhou et al., " $\mathrm{m}^{6} \mathrm{~A}$ Demethylase ALKBH5 Maintains Tumorigenicity of Glioblastoma Stemlike Cells by Sustaining FOXM1 Expression and Cell Proliferation Program," Cancer Cell, vol. 31, no. 4, pp. 591-606.e6, 2017.

[24] H. Zhu, X. Gan, X. Jiang, S. Diao, H. Wu, and J. Hu, “ALKBH5 inhibited autophagy of epithelial ovarian cancer through miR7 and BCL-2," Journal of Experimental \& Clinical Cancer Research, vol. 38, no. 1, p. 163, 2019.

[25] B. B. Hu, X. Y. Wang, X. Y. Gu et al., " $\mathrm{N}^{6}$-methyladenosine $\left(\mathrm{m}^{6} \mathrm{~A}\right)$ RNA modification in gastrointestinal tract cancers: roles, mechanisms, and applications," Molecular Cancer, vol. 18, no. 1, p. 178, 2019.

[26] Y. Su, J. Huang, and J. Hu, "m6A RNA methylation regulators contribute to malignant progression and have clinical prognostic impact in gastric cancer," Frontiers in Oncology, vol. 9, p. 1038, 2019.

[27] Q. Meng, S. Shi, C. Liang et al., "Abrogation of glutathione peroxidase- 1 drives EMT and chemoresistance in pancreatic cancer by activating ROS-mediated Akt/GSK3 $\beta /$ Snail signaling," Oncogene, vol. 37, no. 44, pp. 5843-5857, 2018.

[28] H. F. Wang, M. J. Kuang, S. J. Han et al., "BMP2 modified by the $\mathrm{m}^{6} \mathrm{~A}$ demethylation enzyme ALKBH5 in the ossification of the ligamentum flavum through the AKT signaling pathway," Calcified Tissue International, vol. 106, no. 5, pp. 486493, 2020.

[29] B. Tang, Y. Yang, M. Kang et al., " $m^{6}$ A demethylase ALKBH5 inhibits pancreatic cancer tumorigenesis by decreasing WIF-1 RNA methylation and mediating Wnt signaling," Molecular Cancer, vol. 19, no. 1, p. 3, 2020.

[30] X. Liu, L. Liu, Z. Dong et al., "Expression patterns and prognostic value of $\mathrm{m}^{6} \mathrm{~A}$-related genes in colorectal cancer," American Journal of Translational Research, vol. 11, no. 7, pp. 39723991, 2019.

[31] S. H. Cho, M. Ha, Y. H. Cho et al., "ALKBH5 gene is a novel biomarker that predicts the prognosis of pancreatic cancer: a retrospective multicohort study," Annals of Hepato-BiliaryPancreatic Surgery, vol. 22, no. 4, pp. 305-309, 2018. 